\title{
Estudos de contato no GT de Sociolinguística
}

\section{Contact studies in the Sociolinguistics WG}

\author{
Mônica Maria Guimarães Savedra \\ Universidade Federal Fluminense, Niterói, Rio de Janeiro, Brasil
}

Karen Pupp Spinassé

Universidade Federal do Rio Grande do Sul, Porto Alegre, Rio Grande do Sul, Brasil

Resumo: O presente artigo é parte do número especial sobre o Grupo de Trabalho (GT) de Sociolinguística da Associação Nacional de Pós-Graduação e Pesquisa em Letras e Linguística (ANPOLL) ao longo de seus 35 anos de existência. Buscamos traçar aqui um perfil das pesquisas feitas na área do multi/plurilinguismo e do contato linguístico que vêm sendo reportadas no GT, tentando fazer uma rápida explanação teórica de pontos basilares bem como um resgate histórico de momentos e temas desse âmbito. O objetivo é dar visibilidade às pesquisas e discussões sobre os assuntos elencados (multi/plurilinguismo e contato linguístico) e suas temáticas afins (variação, mudança, identidade, políticas linguísticas etc.), as quais, atualmente, estão reunidas no assim denominado Eixo 2 do GT, intitulado "Contato, Variação e Identidade". Assim, pretendemos traçar um perfil histórico do Eixo e contribuir na divulgação das pesquisas em sociolinguística feitas nos programas de pós-graduação de universidades brasileiras.

Palavras-chave: Sociolinguística de Contato; Contato Linguístico; Multilinguismo; Plurilinguismo; Línguas em Situação Minoritária

\begin{abstract}
The present article is part of a special issue about the Working Group (GT) for Sociolinguistics of the Associação Nacional de PósGraduação e Pesquisa em Letras e Linguística (ANPOLL) throughout its 35 years of existence. We aim here to outline a profile of the researches done in the area of multi/plurilingualism and language contact that have been reported in the GT, trying to make a short theoretical explanation of basic points as well as a historical review of moments and themes of the field. The goal is to give visibility to the researches and the discussions on the mentioned issues (multi/plurilingualism and linguistic contact) and their related themes (variation, change, identity, language policies, etc.), which are currently gathered in the so-called Axis 2 (Eixo 2) of the WG, entitled Contato, Variação e Identidade ("Contact, Variation and Identity"). Thus, we intend to draw a historical profile of the Axis and contribute to the dissemination of the research in sociolinguistics conducted in graduate programs at Brazilian universities.
\end{abstract}


Keywords: Contact Sociolinguistics; Language Contact; Multilingualism; Plurilingualism; Minority languages

\section{Apresentação}

Nos 35 anos de história do Grupo de Trabalho (GT) de Sociolinguística da Associação Nacional de Pós-Graduação e Pesquisa em Letras e Linguística (ANPOLL), a configuração do grupo foi se modificando, de acordo com o desenvolvimento das pesquisas na área, tanto em nível nacional como internacional, e o agrupamento das temáticas também variou ao longo dos anos.

A partir da última configuração, proposta em 2016, o GT foi dividido em quatro eixos. Neste capítulo, trataremos do desenvolvimento do Eixo 2, denominado "Contato, Variação e Identidade", o qual, atualmente sob nossa coordenação, busca reunir pesquisadores que se ocupem de questões relacionadas à variação linguística, à mudança e à identidade, decorrentes de contato linguístico. Isso engloba um grande espectro de temáticas, envolvendo, principalmente, a diversidade linguística em situações de contato, com destaque para as línguas em situação minoritária. Neste capítulo, portanto, pretendemos mostrar como o tema do eixo vem sendo tratado durante as mais de três décadas de existência e apontar, sempre que possível, as áreas temáticas de maior incidência.

\section{Considerações iniciais}

Observando o histórico de pesquisas vinculadas ao GT, podemos dizer que o tema do Contato Linguístico sempre esteve presente e numericamente bem representado. $\mathrm{O}$ que entendemos hoje por esse conceito baseia-se em diferentes estudos, partindo de autores seminais da segunda metade do século XX, tais como Weinreich (1953), Haugen (1959) e Mackey (1980), bem como de estudos mais recentes. Alguns autores, por exemplo, costumam utilizar a terminologia language contact ("contato linguístico" - cf. THOMASON, 2001) para denominar esse campo de estudo, focando na interação entre os falantes de diferentes línguas; outros autores optam por utilizar o termo contact linguistics ("linguística de contato" - cf. WINFORD, 2003), partindo de uma perspectiva 
mais ampla, na qual o foco está na área de investigação - a qual engloba o contato de línguas (cf. SAVEDRA, GAIO, NETO, 2015).

Ao se pensar em contato linguístico (doravante CL), é necessário ter em mente que as línguas entram em contato porque pessoas estão em contato. Ou seja, o CL e todos os fenômenos que dele provêm são um resultado natural da interação social entre indivíduos, sendo, portanto, um evento constante e inevitável. Assim, independentemente do enfoque da nomenclatura, estuda-se, nessa área, a influência mútua que indivíduos, grupos de indivíduos e suas variedades desempenham uns sobre os outros quando em contato. E analisando essas questões com base no referencial teórico e metodológico da Sociolinguística, temos o que denominamos "Sociolinguística de Contato" (cf. SAVEDRA, 2020; SAVEDRA, CHRISTINO, PUPP SPINASSÉ, ARAÚJO, 2021), área na qual o supracitado Eixo 2 do GT vem se consolidando.

A convivência entre duas ou mais línguas pode ocorrer tanto no plano individual, quando uma pessoa domina mais de uma língua, quanto no plano social, quando um mesmo ambiente (lar, comunidade, país...) reúne duas ou mais línguas. Nesse sentido, costuma-se fazer, nos estudos de Sociolinguística de Contato em âmbito nacional e internacional, uma distinção entre os termos Plurilinguismo, o qual se refere à dimensão individual, e Multilinguismo, o qual remete à dimensão social. ${ }^{1}$ Com essa classificação, contudo, a teoria não faz diferença entre a quantidade de línguas faladas pelo indivíduo ou presentes em dada localidade, podendo os termos Plurilinguismo e Multilinguismo substituir "bilinguismo", respectivamente, como um sinônimo.

Nesse viés do contato entre diferentes línguas, como mencionado acima, o Eixo 2 reúne vários pesquisadores que estudam diferentes contextos e situações de contato (entre variedades nacionais, regionais e/ou dialetais, bem como entre diferentes estratos linguísticos, como línguas dominantes e/ou línguas em situação minoritária²). Em um país multilíngue como o nosso, onde diferentes línguas estão em contato constante com o

\footnotetext{
${ }^{1}$ Essa terminologia é proposta e disseminada a partir da Carta Europeia do Plurilinguismo, disponível em: https://www.observatoireplurilinguisme.eu/images/Charte/Charteplurilinguisme_ptV2.13.pdf. Acesso em: 01 mar. 2021.

${ }^{2}$ De acordo com Savedra e Pupp Spinassé (no prelo), utilizamos o termo "línguas em situação minoritária" para denominar tanto as línguas de fato "minoritárias", ou seja, línguas que possuem um número de falantes inferior ao de outras línguas representadas em maior número no mesmo território, quanto as línguas ditas "minorizadas", ou seja, aquelas que são tratadas como minoritárias não por uma questão numérica, mas por uma questão política e social, uma vez que sofrem de desprestígio.
}

Revista da Anpoll, Florianópolis, v. 52, n. esp., p. 103-117, jan.-dez., 2021 | 105 
português e mesmo entre si, nossa área abarca diversas variedades e diversos enfoques de pesquisa sociolinguística.

Existem, no Brasil, inúmeras línguas indígenas, várias línguas de imigração, três línguas afro-brasileiras e duas línguas de sinais, totalizando cerca de 255 línguas brasileiras $^{3}$ - sem contar as variedades de contato faladas em regiões de fronteira, variedades do português brasileiro, duas línguas crioulas alóctones, bem como inúmeras línguas de herança praticadas no dia a dia no país. Entretanto, a maior parte da população ainda cresce em uma situação social monolíngue: apenas $1,5 \%$ da população fala outras línguas em casa além do português, sendo as comunidades de fala de línguas indígenas, africanas ou de imigração, portanto, proporcionalmente pequenas, se levarmos em conta o tamanho do território e o número de habitantes.

Para auxiliar na visibilidade dessa pluralidade, teve início, no início deste século, uma política de reconhecimento da diversidade linguística brasileira e, no período de 2002 até o presente, houve o reconhecimento de 17 línguas cooficiais em diferentes municípios de nosso país, sendo onze delas indígenas (Tukano, Nheengatu, Baniwa, Guarani, Akwê Xerente, Macuxi, Wapichana, Ticuna, Ingaricó, Saterê Mauê e Mebêngokrê (Kayapó)) e seis de imigração (Pomerano, Talian, Alemão, Hunsrückisch (Hunsriqueano), Plattdüütsch (Vestfaliano) e Dialeto Trentino). ${ }^{4}$ Devido às suas limitações, essa política pode não ser suficientemente representativa, em termos de política pública, posto que todos os decretos e leis que cooficializam essas línguas se dão em nível municipal. Contudo, tais iniciativas devem ser saudadas, uma vez que tal legislação já permite a inserção dessas línguas no ensino e no uso profissional e administrativo das respectivas localidades.

Algumas dessas línguas, como as indígenas, têm origem no território brasileiro; já as línguas de imigração, por exemplo, como sugerido no próprio nome, foram trazidas para o Brasil por movimentos migratórios, ocorridos principalmente a partir do século XIX com o movimento Brasil-Imigração, e vêm acontecendo até os dias de hoje, com a

\footnotetext{
${ }^{3}$ Esse número foi citado em uma palestra proferida pelo Prof. Dr. Gilvan Müller de Oliveira (UFSC) no âmbito do evento "Abralin Ao Vivo - Linguists Online", em 15 de fevereiro de 2021. O pesquisador ressaltou, contudo, que esse número não pode ser visto como absoluto, uma vez que pode variar de acordo com a metodologia de contagem e classificação. Disponível em: https://www.youtube.com/watch?v=DrERYH3pCXk. Acesso em: 16 fev. 2021.

${ }^{4}$ Dados disponíveis no site do Instituto de Investigação e Desenvolvimento em Política Linguística - IPOL: http://ipol.org.br/lista-de-linguas-cooficiais-em-municipios-brasileiros/. Acesso em 01 de mar. 2021.
}

Revista da Anpoll, Florianópolis, v. 52, n. esp., p. 103-117, jan.-dez., 2021 | 106 
realidade dos refugiados. Mesmo assim, as denominamos línguas brasileiras, devido ao seu histórico recente em território nacional, ao seu status social e à sua situação política, tendo constituído identidades linguísticas próprias - embora ainda não haja uma grande visibilidade em relação a elas ou ao seu status. Nesse sentido, é válido citar o estudo de Savedra e Mazzelli (2017), que já denominam uma língua de imigração como neoautóctone, considerando o conceito antropológico de autoctonia, o conceito geográfico de terra (Land) e o tempo em que a língua já se estabeleceu e vem sendo usada no território.

No Eixo 2, são investigados contextos de contato proveniente da imigração, de contatos de fronteiras, alguns contatos específicos de variedades autóctones com variedades oficiais e variedades de línguas africanas. Na descrição e análise de tais contextos, as questões da identidade e da variação se apresentam como elementos enriquecedores e complementares para interpretação das diferentes situações de contato em estudo. Permeando esses temas, trabalhamos com línguas que sofrem desprestígio e que ainda não contam com estratégias para reconhecimento, manutenção, vitalidade ou salvaguarda - ou contam apenas com estratégias frágeis, em termos de políticas públicas. Nesse sentido, também as políticas linguísticas são um viés de relevância nas pesquisas vinculadas ao eixo.

\section{0 eixo Contato, Variação e Identidade em perspectiva}

O GT de Sociolinguística foi um dos primeiros GTs da ANPOLL, criado junto à Associação em dezembro de 1985 (SAVEDRA, 2010). Desde a sua criação, a temática central do Eixo 2, qual seja o Contato Linguístico, já se evidenciava, posto que o GT foi criado, inicialmente, com o nome de Sociolinguística e Bilinguismo, tendo como objetivo inicial identificar os rumos da Sociolinguística no Brasil.

Seguindo a organização em biênios proposta pela ANPOLL, os próximos anos de nosso GT foi marcado pela consolidação de quatro principais eixos de pesquisa: variação laboviana, estudos de bilinguismo, etnografia e sociolinguística interacional. O contato se colocava presente sobretudo através dos estudos sobre bilinguismo, que vinham para se opor à noção de monolinguismo. Entretanto, nesse momento, evoluímos do conceito do bilinguismo para ideia de plurilinguismo, quando a Constituição de 1988 declarou o

Revista da Anpoll, Florianópolis, v. 52, n. esp., p. 103-117, jan.-dez., 2021 | 107 
Brasil um país plurilíngue e passou a reconhecer estudos de bilinguismo com línguas indígenas autóctones.

Os estudos de bilinguismo assumiram papel importante dentro do GT como linha específica, antecipando-se e preparando as bases para tantas pesquisas que viriam a ser desenvolvidas. A publicação do livro "Fotografias Sociolinguísticas", por Fernando Tarallo, em 1989, é um marco importante na história do nosso grupo. Tarallo divide a obra em quatro partes, de modo a contemplar os eixos de nosso GT à época, a saber: estudos linguístico-sociais; estudos diacrônico-tipológicos; estudos interacionais; e estudos metodológico-conceituais. Nessa obra, a temática do contato linguístico fica contemplada em todas as partes, pois em cada uma podemos identificar estudos que partem das situações de contato para a descrição de situações sociolinguísticas apresentadas na obra.

Dando continuidade às atividades do GT e ao tema do contato Linguístico, a década de 90 foi marcada por grandes avanços nos estudos sobre Heterogeneidade Linguística, então observada sob diferentes enfoques. Os trabalhos desenvolvidos pelos membros do GT já começavam a ultrapassar as linhas definidas no final da década anterior. Era necessário desdobrá-las por causa das inúmeras questões que vinham à baila nas pesquisas desenvolvidas até então. Esse desdobramento teve como consequência a criação de novas áreas a serem especificamente abordadas, tais como Multilinguismo e Línguas/Dialetos em Contato, Etnografia da Fala Interacional, Dialetologia, Sociolinguística Laboviana, Sociolinguística Paramétrica e Mudança Linguística. Nessa época, os estudos de contato, antes concebidos como estudos de bilinguismo, passaram a ser identificados como estudos de pluri/multiliguismo. Nesse contexto, são introduzidos estudos que ainda discutem a distinção entre língua e dialeto como fenômeno linguístico. $\mathrm{Na}$ verdade, atualmente, tal distinção assume contornos sociais e políticos, retomando a posição introduzida por Weinreich (1954).

Como consequência desse desenvolvimento, o tema central da investigação do GT para o biênio 1996-1998 passa a ser a Diversidade Linguística no Brasil. A constatação e assumpção de que nosso país é multilíngue ensejou estudos sobre o plurilinguismo e suas dimensões temporal e histórica (diacronia), bem como social e situacional (variação, atitudes, socioletos e registros).

Revista da Anpoll, Florianópolis, v. 52, n. esp., p. 103-117, jan.-dez., 2021 | 108 
Outro avanço que fica claro em nosso eixo de contato refere-se aos diversos estudos e pesquisas organizados no âmbito da criação de diferentes atlas linguísticos. $\mathrm{O}$ projeto Atlas Linguístico do Brasil (ALiB), desenvolvido pela Universidade Federal da Bahia (UFBA), é um empreendimento de grande amplitude, de caráter nacional, sempre em desenvolvimento, e tem por meta a realização de um atlas geral do Brasil no que diz respeito à língua portuguesa. O ALiB propõe reunir acervos de diferentes usos linguísticos do português brasileiro, permeando a temática de dialetos como referência regional em nosso país, albergando hoje doze Universidades. ${ }^{5}$

Nesse período, também são consolidados Atlas/Cartas de diferentes grupos de contato identificados em várias regiões do país (Alers, NURC, PEUL, Varsul, entre outros), que descrevem a variação e mudança em diferentes situações de contato, envolvendo línguas em situação minoritária e/ou majoritária. Na verdade, tais projetos apontam a variação e mudança identificadas em diferentes contextos de contato no/do Brasil, que apontam a pluralidade linguística de nosso país, sendo todos organizados em uma perspectiva de identificar as diferentes variedades regionais, dialetais etc., que compõem o mosaico multilíngue aqui identificado.

Também na última década do século XX, dois documentos de nível internacional vieram reforçar os estudos desenvolvidos nas pesquisas sobre contato: i) a Carta Europeia das Línguas Regionais ou Minoritárias, concebida pelo Conselho da Europa em 1992, entrando em vigor em 1 de Março de 1998; e ii) a Declaração Universal dos Direitos Linguísticos, aprovada em Barcelona, em 1996, no âmbito da Conferência Mundial dos Direitos Linguísticos, por iniciativa de organizações não governamentais e com o apoio da UNESCO. Tais documentos/ações, lidam diretamente com os temas de pesquisa do nosso Eixo, pois passam a embasar vários estudos que discutem a questão de línguas oficiais, línguas regionais, línguas minoritárias, línguas de imigração e línguas ameaçadas de extinção. Muitos estudos de pesquisadores de nosso GT envolvidos com o tema embasam suas investigações citando tais documentos ou os preceitos trazidos por eles, como o volume temático da Revista Palavra, intitulado "Línguas em Contato", organizado por Heye e Savedra (2003); o livro que trata de "Variação, Mudança e Contato Linguístico no Português da Região Sul”, organizado por Vandresen (2006); o livro de von Borstel (2011), que trata da linguagem sociocultural em diferentes situações de

\footnotetext{
${ }^{5}$ Disponível em: https://alib.ufba.br/historico. Último acesso: 19 fev. 2021
} 
bilinguismo e multilinguismo, enfatizando situações interlinguísticas, culturais e de memória identitária; e o livro organizado por Mello, Tommazo e Altenhofen (2011), que trata de diferentes situações de contato linguístico no Brasil (línguas de imigração, línguas indígenas, línguas africanas, contatos de fronteira...); entre outros.

Além dos estudos acima apontados, foram organizadas publicações no âmbito do GT (cf. RONCARATI, ABRAÇADO, 2003; 2008), que contemplavam os três grandes eixos da época: Variação e Mudança, Contato Linguístico e Dialetologia. Os estudos referentes ao contato foram alocados na parte da obra intitulada "Contato Linguístico", e os temas tratados abordavam questões de bilinguismo e bilingualidade, política e planificação linguística, português de contato do Alto-Xingu, marcas dialetais de fronteira, conceito de transmissão linguística irregular no processo de formação do português brasileiro, entre outros.

O livro "Identidade Social e Contato Linguístico no Português Brasileiro", organizado por Savedra, Martins e da Hora (2015) deu sequência às duas publicações anteriores. Nele, o contato linguístico é representado por estudos sobre o pluricentrismo linguístico, pela descrição de situações de contato do português com línguas de imigração e contatos de fronteira de nosso país.

Ainda no âmbito das publicações do nosso GT, a edição $n^{\circ} 1$ do Volume 10 da revista Letrônica, da PUCRS (2017), publica alguns estudos que se enquadram em nosso Eixo. Um trata da questão das crenças e identidades e outro estuda o contato e a diversidade linguística em léxico regional.

A última publicação realizada pelo GT em conjunto foi a edição do livro intitulado "Dimensões e experiências em sociolinguística", organizado por Machado Vieira e Wiedemer (2019). Nele, alguns trabalhos representam o Eixo 2 ao tratar de diferentes temas de variedade em diferentes situações de contato, tanto em nível nacional como internacional. A etnicidade linguística e cultural de determinados falantes no uso de diferentes línguas e a questão das atitudes e do uso linguístico também são temas abordados na publicação.

Além dessas publicações, também destacamos, na primeira década do século XXI, o I Encontro Internacional do GT de Sociolinguística da ANPOLL, realizado na PUCRio, entre 29 de julho e 03 de agosto de 2007. O evento contou com a presença de pesquisadores de renome internacional, tais como Louis Jean Calvet, da Université Aix- 
en-Provence (França), Ulrich Ammon, da Universität Duisburg-Essen (Alemanha), e Norbert Dittmar, da Freie Universität Berlin (Alemanha). Nesse evento, o eixo de contato se fortaleceu com estudos sobre línguas pluricêntricas e suas variedades nacionais, regionais e dialetais, bem como sobre política e planificação linguística.

Com o avanço das pesquisas, se consolidaram três vertentes de estudo para o GT: Dialetologia, Sociolinguística Variacionista e Multilinguismo, que foram as bases para a reformulação das pesquisas em eixos, já a partir do início da segunda década do século XXI. Inicialmente, a nova proposta englobava 5 eixos, sendo um deles "Contato Linguístico". Mas foi a partir de 2016 que o GT assumiu a configuração que tem, relativamente, até hoje:

Eixo 1 - Variação e Mudança Linguísticas

Eixo 2 - Contato, Variação e Identidade

Eixo 3 - Sociolinguística e Ensino

Eixo 4 - Teorias e métodos para o estudo da variação e mudança linguísticas: estado da arte e perspectivas > Questões teóricas e metodológicas (atualmente)

A partir dessa nova configuração, identificamos algumas publicações de livros e periódicos organizados dentro da temática e por pesquisadores do Eixo 2, tais como o livro "Repertórios plurilíngues em situação de contato", organizado pelo Laboratório de Pesquisa em Contato Linguístico da UFF (2018) e os seguintes periódicos ${ }^{6}$ o Caderno de Letras da UFF, vol. 26/n. 53 (2016), ${ }^{7}$ com o título "Línguas e Culturas em Contato", e o vol. 32/n. 62 (2021), que está em organização e será publicado sob o título de "Multilinguismo, Discurso e Direitos Linguístico"; 8 a Revista Gragoatá, também da UFF, em seus números 42 (vol. 22, 2017) ${ }^{9}$ e 54 (vol. 26, 2021) ${ }^{10}$, intitulados, respectivamente, "Imigração, práticas de linguagem e políticas linguísticas" e "Línguas em contato:

\footnotetext{
${ }^{6}$ Informaremos os endereços eletrônicos de cada uma das revistas, todas acessadas pela última vez no dia 03 de março de 2021.

${ }^{7} \mathrm{Cf}$. https://periodicos.uff.br/cadernosdeletras/issue/view/2217.

${ }^{8} \mathrm{Cf}$. https://periodicos.uff.br/cadernosdeletras/announcement/view/436.

${ }^{9} \mathrm{Cf}$. https://periodicos.uff.br/gragoata/issue/view/1764.

${ }^{10} \mathrm{Cf}$. https://periodicos.uff.br/gragoata/issue/view/2404.
} 
perspectivas sociolinguísticas"; a Revista Organon, da UFRGS, vol. 32/n. 62 (2017), ${ }^{11}$ com o título "Plurilinguismo na Educação e na sociedade"; a Revista Working Papers em Linguística, da UFSC, vol. 18/n. 1 (2017), ${ }^{12}$ com o título "Linguística e História", que albergou vários estudos de pesquisadores do nosso Eixo que tratam do contato de línguas de imigração; a revista Linguagem \& Ensino, da UFPel, vol. 23/n. 4 (2020), ${ }^{13}$ intitulada "Línguas minoritárias"; e o dossiê temático da Revista Cor das Letras de 2020 (vol. 21/n. 1), ${ }^{14}$ com o título "Políticas e Contatos Linguísticos". Em breve também será publicado o dossiê temático "Línguas Minoritárias no Brasil" (vol. 14/n. 37, 2021) da Revista de Letras Norte@mentos, da Unemat. ${ }^{15}$

Finalmente, no intuito de identificar o estado da arte da temática que conduz o Eixo, fizemos uma busca entre os grupos de pesquisa cadastrados junto ao CNPq e entre os Programas de Pós-Graduação registrados na CAPES. A consulta no site do Diretório dos Grupos - $\mathrm{CNPq}^{16}$ foi realizada por títulos de Grupos de Pesquisa bem como por Linhas aos quais os mesmos estão vinculados, com base na busca das seguintes palavraschave: "Contato", "Contato e Variação" e "Identidade". Os resultados podem ser visualizados na tabela a seguir:

Tabela 1 - Grupos de Pesquisa com temática abordada no atual Eixo 2

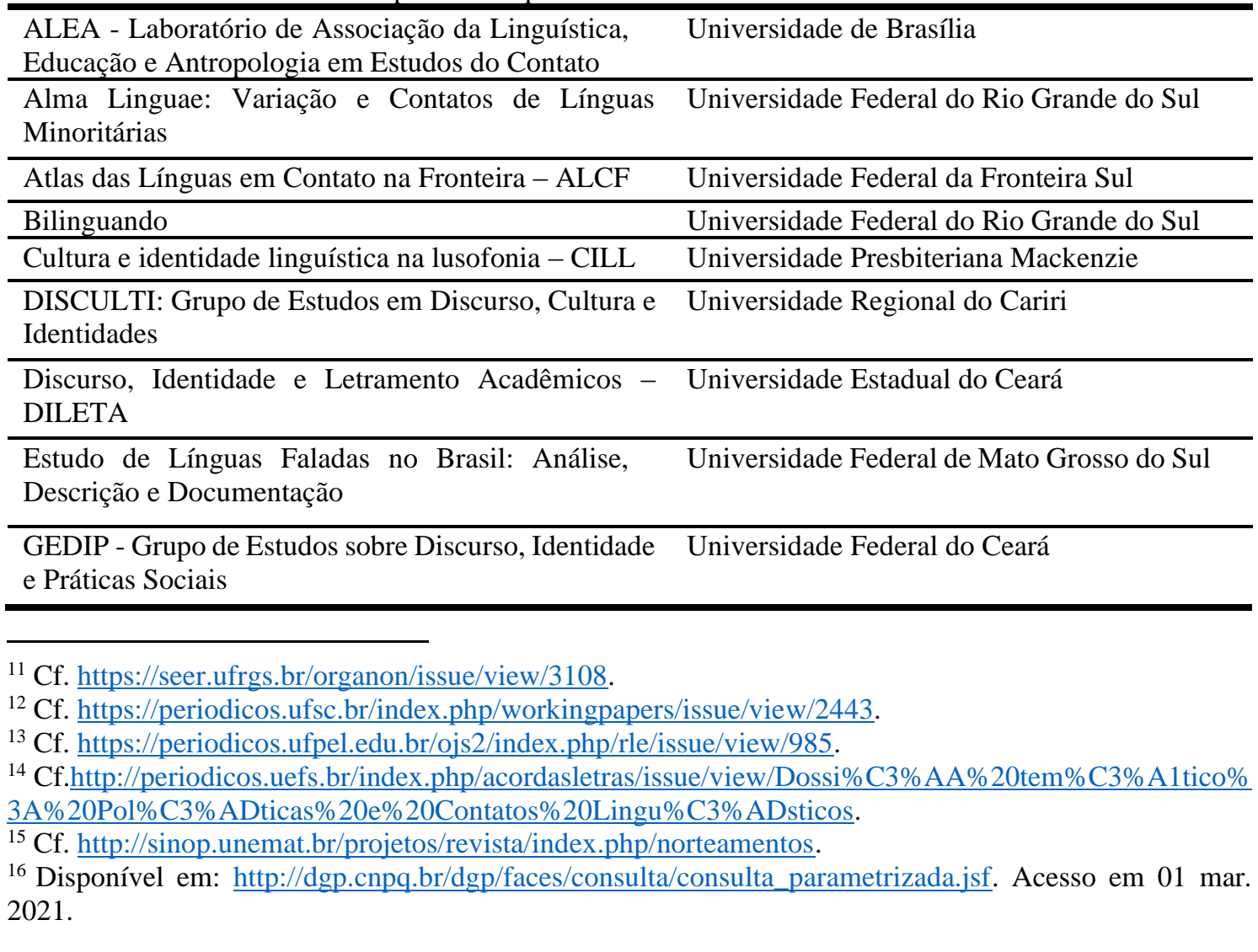




\begin{tabular}{|c|c|}
\hline Grupo Atlas Linguístico do Amapá - ALAP- Fase II & Universidade Federal do Amapá \\
\hline $\begin{array}{l}\text { Grupo de Estudos do Português Popular da Bahia - } \\
\text { GEPPOP }\end{array}$ & Universidade Federal do Recôncavo da Bahia \\
\hline Grupo de Pesquisa em Contato Linguístico & Universidade Federal da Paraíba \\
\hline $\begin{array}{l}\text { Grupo de pesquisa em Discurso, Ensino, Línguas, } \\
\text { Culturas e Identidades - DELIC }\end{array}$ & Universidade Federal do Amapá \\
\hline $\begin{array}{l}\text { Grupo de Pesquisa Laboratório de Estudos em } \\
\text { Políticas Linguísticas, Interação e Desenvolvimento } \\
\text { Humano }\end{array}$ & $\begin{array}{l}\text { Instituto Federal de Educação, Ciência e } \\
\text { Tecnologia Baiano }\end{array}$ \\
\hline $\begin{array}{l}\text { História das ideias linguísticas (Brasil e Portugal) e } \\
\text { identidade nacional }\end{array}$ & Pontifícia Universidade Católica de São Paulo \\
\hline Identidade, tolerância e emancipação & Universidade Luterana do Brasil \\
\hline $\begin{array}{l}\text { Laboratório de pesquisas em contato linguístico - } \\
\text { LABPEC }\end{array}$ & Universidade Federal Fluminense \\
\hline $\begin{array}{l}\text { Laboratório "Linguagem, Interação, Cultura e } \\
\text { Cognição" }\end{array}$ & Universidade de São Paulo \\
\hline Letramento e Etnografia & $\begin{array}{l}\text { Universidade Federal do Rio Grande do } \\
\text { Norte }\end{array}$ \\
\hline $\begin{array}{l}\text { Letramentos acadêmicos em línguas no ensino } \\
\text { superior (LALES) }\end{array}$ & Universidade de Brasília \\
\hline $\begin{array}{l}\text { Letramento, etnografia, interação, aprendizagem e } \\
\text { multilinguismo (LEIAM) }\end{array}$ & Universidade Estadual de Maringá \\
\hline Letramentos, identidades, diversidades & Universidade Federal do Pará \\
\hline $\begin{array}{l}\text { Letramentos e Práticas Discursivas e Culturais - } \\
\text { LEPDIC }\end{array}$ & Universidade de Pernambuco \\
\hline Lingua(gem), discurso e subjetividade & Universidade Federal da Fronteira Sul \\
\hline Linguagem e identidade: Abordagens Pragmáticas & Universidade Estadual de Campinas \\
\hline Línguas em Contato & Universidade Federal de Pelotas \\
\hline MOBILANG: Mobilidades e contatos de línguas & Universidade de Brasília \\
\hline Núcleo de Tipologia e Línguas Indígenas & Universidade de Brasília \\
\hline $\begin{array}{l}\begin{array}{l}\text { Português como língua de acolhimento e a } \\
\text { performance identitária }\end{array} \\
\end{array}$ & Universidade Estadual de Santa Cruz \\
\hline $\begin{array}{l}\text { Práticas formativas e profissionais: identidades e } \\
\text { representações nos discursos }\end{array}$ & $\begin{array}{l}\text { Pontifícia Universidade Católica de Minas } \\
\text { Gerais }\end{array}$ \\
\hline
\end{tabular}

Fonte: elaborado pelas autoras de acordo com os dados obtidos do $\mathrm{CNPq}$

Como a busca se deu pelas palavras-chave acima citadas, estando elas no título do Grupo ou no nome da Linha de Pesquisa à qual ele pertence, não necessariamente os grupos aqui listados estão vinculados ao nosso GT. Contudo, podemos observar diferentes enfoques e pesquisas diversas que abordam a questão do contato e da identidade. Isso nos leva a concluir como é diverso e amplo o espectro dos estudos de contato em nosso país, presentes em todas as regiões e em diferentes tipos de instituições. 
$\mathrm{Na}$ consulta aos Programas de Pós-Graduação vinculados à CAPES ${ }^{17}$, encontramos, atualmente, 159 programas cadastrados na área de Linguística e Letras. Algumas das linhas de pesquisa dos diversos PPGs carregam em seus nomes referências aos temas do eixo 2, tais como Contato, Identidade, Políticas Linguísticas etc. Listamos alguns exemplos na tabela abaixo:

Tabela 2 - Linhas de pesquisa com temas do Eixo 2 nos PPGs do país

\begin{tabular}{cl}
\hline Instituição & \multicolumn{1}{c}{ Linhas } \\
\hline UFF & HISTÓRIA, POLÍTICA E CONTATO LINGUÍSTICO \\
\hline UFSC & CONTATO, VARIAÇÃO E MUDANÇA LINGUÍSTICA \\
\hline UFSC & POLÍTICA LINGUÍSTICA \\
\hline UFMS & LINGUAGENS, IDENTIDADES E ENSINO \\
\hline UFPR & LINGUAGENS, CULTURAS E IDENTIDADES: ENSINO E APRENDIZAGEM \\
\hline UFBA & DIALETOLOGIA E SOCIOLINGUÍSTICA \\
\hline UFRGS & SOCIOLINGUÍSTICA \\
\hline
\end{tabular}

Fonte: elaborado pelas autoras com dados obtidos através da CAPES

\section{Considerações finais}

Após apresentação da história e do percurso dos trabalhos desenvolvidos no atual Eixo 2 do GT de Sociolinguística, acreditamos ter possibilitado um panorama não somente histórico como também desvelador sobre o perfil do Eixo e dos estudos realizados na área do multi/plurilinguismo, temas centrais que tratam de Contato, Identidade e Variação. Acreditamos ter alcançado o objetivo proposto, qual seja, o de dar visibilidade às pesquisas e discussões sobre os assuntos elencados na área de contato linguístico e suas temáticas afins (variação, mudança, identidade, políticas linguísticas etc.), como demonstrado nos trabalhos apresentados, bem como nas tabelas que elaboramos sobre Grupos de Pesquisa do CNPq e sobre Programas de Pós-Graduação do nosso país.

\footnotetext{
${ }^{17}$ Disponível em: https://sucupira.capes.gov.br/sucupira/public/consultas/coleta/programa/listaPrograma.jsf. Acesso em 01 mar. 2021.
} 
Com certeza, essa digressão aqui proposta contribui significativamente para a divulgação das pesquisas em contato linguístico no âmbito do GT de Sociolinguística da ANPOLL.

\section{Agradecimentos}

MMGS é Cientista do nosso estado (CNE) pela Fundação Carlos Chagas de Amparo à Pesquisa do Estado do Rio de Janeiro (FAPERJ) e bolsista de produtividade do Conselho Nacional de Desenvolvimento Científico e Tecnológico (CNPq).

\section{Contribuição}

Mônica Maria Guimarães Savedra: Conceptualização, Curadoria de Dados, Investigação, Metodologia, Visualização, Escrita - rascunho original, Escrita - análise e edição; Karen Pupp Spinassé: Conceptualização, Curadoria de Dados, Investigação, Metodologia, Visualização, Escrita - rascunho original, Escrita - análise e edição.

\section{Referências}

HAUGEN, Einar. Language Planning in Modern Norway (1959 [1961]). In: DIL, A. S. The Ecology of Language: Essays by Einar Haugen. Stanford: Stanford University Press. 1972. p. 133-147.

HEYE, Jürgen; SAVEDRA, Mônica Maria Guimarães (Orgs.). Revista Palavra, n. 11, Volume Temático "Línguas em Contato", 2003.

MACHADO VIEIRA, Marcia dos S.; WIEDEMER, Marcos Luiz (Orgs.). Dimensões e Experiências em Sociolinguística. Blücher: Open Access. 2019.

MACKEY, William Francis. The Ecology of Language Shift (1980). In: FILL, Alwin; MÜHLHÄUSLER, Peter (Orgs.). The Ecolinguistics Reader. London: Continuum. 2001. p. 67-74.

MELlO, Heliana; ALTENHOFEN, Cléo V.; RASO, Tommaso (Orgs.). Os Contatos linguísticos no Brasil. Belo Horizonte: Ed. UFMG. 2011.

RONCARATI, Claudia; ABRAÇADO, Jussara. Português Brasileiro II: Contato linguístico, Heterogeneidade e História. Niterói: Eduff. 2008. 
RONCARATI, Claudia; ABRAÇADO, Jussara. Português Brasileiro: Contato linguístico, Heterogeneidade e História. Rio de Janeiro: 7 Letras. 2003.

SAVEDRA, Mônica Maria Guimarães. Estudos e Pesquisas em Sociolinguística no contexto plurilíngue do Brasil. Revista da ANPOLL: 25 anos. Linguística: percursos e perspectivas, v. 1, n. 29, p. 219-234, 2010.

SAVEDRA, Mônica Maria Guimarães. Language vitality and transculturalization of european immigrant minorities: pomeranian in Brazil. Diadorim, Rio de Janeiro, v. 22, n. 1, p. 79-92, 2020.

SAVEDRA, Mônica Maria Guimarães; CHRISTINO, Beatriz; PUPP SPINASSÉ, Karen; ARAÚJO, Silvana S. de Farias. Estudos em sociolinguística de contato no Brasil: a diversidade etnolinguística em debate, Cadernos de Linguística. no prelo.

SAVEDRA, Mônica Maria Guimarães; GAIO, Mario L. M.; NETO, Marciolino E. C. Contato Linguístico e imigração no Brasil: fenômenos de manutenção/revitalização, language shift e code-switching. Veredas on-line, Juiz de Fora, v. 19, n.1, p. 71-91, 2015.

SAVEDRA, Mônica Maria Guimarães; MARTINS, Marco Antônio; DA HORA, Dermeval. Identidade Social e Contato Linguístico no Português Brasileiro. Rio de Janeiro: Eduerj. 2015.

SAVEDRA, Mônica Maria Guimarães; MAZZELLI, Leticia R. A língua pomerana em percurso histórico brasileiro: uma variedade (neo)autóctone. Working Papers em Linguística, Florianópolis, v. 18, n. 1, p. 6-22, jan./jul. 2017.

SAVEDRA, Mônica Maria Guimarães; PUPP SPINASSÉ, Karen. O ensino de variedades germânicas em contextos de contato linguístico: conceitos, princípios e diretrizes. In: KRETSCHMER, Johannes; SAVEDRA, Mônica M. G.; BOLACIO FILHO, Ebal Sant'Anna; FERREIRA, Mergenfel Vaz; LAGES, Susana Kampff. Travessias, Encontros, Diálogos nos Estudos Germanísticos no Brasil. Niterói: Eduff/ABEG. no prelo.

TARALLO, Fernando (Orgs.). Fotografias sociolinguísticas. Campinas: Pontes. 1989.

THOMASON, Sarah G. Language Contact: An Introduction. Edinburgh: Edinburgh University Press. 2001.

VANDRESEN, Paulino (Orgs.). Variação, Mudança e Contato Linguístico no português da Região Sul. Pelotas: EDUCAT. 2006.

VON BORSTEL, Clarice. A linguagem sociocultural do Brasildeutsch. São Carlos: Pedro \& João Editores. 2011.

WEINREICH, Uriel. Is a Structural Dialectology Possible? Word 10, p. 388-400, 1954.

Revista da Anpoll, Florianópolis, v. 52, n. esp., p. 103-117, jan.-dez., 2021 | 116 
WEINREICH, Uriel. Languages in contact, findings and problems. New York: Linguistic Circle of New York. 1953.

WINFORD, Donald. An Introduction to Contact Linguistics. Oxford: Blackwell. 2003.

Recebido em: 10 de dezembro de 2020 Aceito em: 31 de maio de 2021 Publicado em setembro de 2021

Mônica Maria Guimarães Savedra

E-mail: msavedra@id.uff.br

ORCID: https://orcid.org/0000-0003-1056-9391

Karen Pupp Spinassé

E-mail: spinasse@ufrgs.br

ORCID: https://orcid.org/0000-0002-1379-8387 